\title{
CEFALÉIA RELACIONADA À DISFUNÇÃO TEMPOROMANDIBULAR
}

Tatiana SAFANELLI; Lilian CUSTÓDIO

As disfunções temporomandibulares são distúrbios que acometem o sistema mastigatório, especificamente a ATM e músculos da mastigação. A cefaléia é um dos principais sintomas relacionados com a DTM. As cefaléias são classificadas em primárias e secundárias. As primárias não possuem etiologia detectável e as secundárias originam-se de alterações patológicas. É nesse último grupo que estão incluídas as cefaléias relacionadas a DTM. As causas mais comuns de DTM são hábitos parafuncionais, estresse emocional, traumas, fatores oclusais e sistêmicos. O tratamento inclui terapia com dispositivo interoclusal (DIO) e medidas terapêuticas. O DIO consiste em uma placa de acrílico estabilizadora que propicia relaxamento muscular, aliviando a sintomatologia. Ela elimina interferências oclusais proporcionando estabilidade e causando harmonia entre côndilo, disco e fossa. Outra alternativa terapêutica é a utilização de agentes farmacológicos como antiinflamatórios e analgésicos. Este trabalho objetiva analisar a relação entre DTM e cefaléia, além de estabelecer a utilização do DIO como forma de tratamento para remissão da sintomatologia. Existe uma correlação positiva entre placa oclusal estabilizadora, relaxamento muscular e remissão da dor. Esse relaxamento muscular persiste por, aproximadamente, 30 dias após a retirada da placa. Os fármacos podem ser prescritos conjuntamente com o DIO, mas nunca de forma isolada. 